This PDF is a selection from a published volume from the National Bureau of Economic Research

Volume Title: Producer Dynamics: New Evidence from Micro Data

Volume Author/Editor: Timothy Dunne, J. Bradford Jensen, and Mark J. Roberts, editors

Volume Publisher: University of Chicago Press

Volume ISBN: 978-0-226-17256-9

Volume URL: http://www.nber.org/books/dunn05-1

Conference Date: April 8-9, 2005

Publication Date: January 2009

Chapter Title: The Role of Retail Chains: National, Regional and Industry Results

Chapter Author: Ronald S. Jarmin, Shawn D. Klimek, Javier Miranda

Chapter URL: http://www.nber.org/chapters/c0487

Chapter pages in book: (237 - 262) 


\section{The Role of Retail Chains \\ National, Regional, and Industry Results}

Ronald S. Jarmin, Shawn D. Klimek, and Javier Miranda

\subsection{Introduction}

The U.S. retail trade sector has undergone dramatic change in recent decades. The share of U.S. civilian employment associated with retail trade has increased from 12.6 percent in 1958 to 16.4 percent in 2000, and retail employment has more than doubled. In addition to this growth, the sector has been affected in important ways by changes in technology and societal trends such as suburbanization and changes in consumer preferences.

The structure of retail markets, affected by all these forces, has been continuously evolving. A major feature of this evolution has been the growth of large national retail chains. This has been coupled with a dramatic decrease in the share of retail activity accounted for by small single location or mom-and-pop stores. In 1948, single location retail firms accounted for 70.4 percent of retail sales, but only 60.2 percent by 1967 (U.S. Census Bureau 1971). By 1997, this share had fallen further to 39 percent. In 1948, large retail firms with more than 100 establishments accounted for 12.3 percent of retail sales, but this number grew to 18.6 percent in 1967 (U.S.

Ronald S. Jarmin is chief economist and chief, Center for Economic Studies (CES) at the U.S. Census Bureau. Shawn D. Klimek is a senior economist at the Center for Economic Studies (CES) at the U.S. Census Bureau. Javier Miranda is an economist at the Center for Economic Studies (CES) at the U.S. Census Bureau.

This chapter was written by Census Bureau staff. It has undergone a more limited review than official Census Bureau publications. Any views, findings, or opinions expressed in this chapter are those of the authors and do not necessarily reflect those of the Census Bureau. We would like to thank Jeff Campbell, Tim Dunne, Mark Roberts, Brad Jensen, Emek Basker, and participants at the NBER-Conference on Research in Income and Wealth (CRIW) and the Business Data Linking Conference in Cardiff, Wales for useful comments. Any remaining errors are solely the responsibility of the authors. 
Census Bureau 1971). By 1997, these large retail firms account for 36.9 percent of all retail sales.

Many observers have noted the dramatic changes in the structure of retail markets. Among the more important changes is the rise of big box national retail chains, such as Wal-Mart. However, the figures cited above indicate that the trend away from mom-and-pops towards national chains has been underway since long before the advent of the big box stores. The trend also predates the wide scale adoption of information technology by retailers. Rather, the rise of technologically sophisticated national retail chains like Wal-Mart, Toys-R-Us, and Home Depot is simply part of the larger trend - underway for some time-towards larger scale retail firms.

What is clear is that the dynamics of the changes during the post-World War II era in the retail sector are not well documented. This is due, in part, to a lack of comprehensive firm level longitudinal data that would allow researchers to describe and analyze the structure of retail markets. In this chapter, we use a recently constructed Census Bureau data set, the Longitudinal Business Database (LBD), to examine local retail markets over the 1976 to 2000 period. We believe these are the best data available to study trends across the entire U.S. retail sector over a long time period. These data are not perfect, however, and we discuss several remaining data gaps and measurement issues.

The chapter proceeds as follows. In section 6.2 we summarize some of the trends that have characterized the retail sector in the United States over the last several decades. We discuss data and measurement issues in section 6.3. We provide some basic but informative descriptions of different types of firms in national and regional retail markets in section 6.4 and offer conclusions and discuss future research in section 6.5.

\subsection{Trends in the U.S. Retail Sector}

Like the rest of the U.S. economy, the retail trade sector has been undergoing significant structural changes in recent decades. However, since everyone is a consumer and interacts with businesses in the retail sector regularly, these changes have not come without controversy. The trend away from smaller scale mom-and-pop retailers and towards large national chains of big box stores is often blamed in the popular media for a host of social, economic, and environmental ills. Our purpose is not to participate in this debate, but to improve the tools researchers and policymakers have at their disposal to measure changes in the structure of the retail sector and to begin to understand the forces that underlie them.

\subsubsection{Basic Features of the Recent Evolution of U.S. Retail Markets}

To lay the groundwork for the rest of the chapter, it is useful to review, from a more macro perspective, what has been going on in the retail sector 




Fig. 6.1 U.S. retail employment and share of the employed civilian population

Sources: Statistical Abstract of the U.S., Economic Report of the President, and own calculations from the LBD.

over the last several decades. Figure 6.1 shows the growth of U.S. retail employment from 1958 to 2000 . We see that, on the Standard Industrial Classification (SIC) ${ }^{1}$ basis, retail employment grew from just under 8 million in 1958 to over 22 million in 2000. The figure also shows that the share of retail in overall U.S. employment has gone up from 12.6 percent to 16.4 percent.

Retail employment saw a dramatic increase of roughly 175 percent over the 1958 to 2000 period but, as shown in figure 6.2, the number of retail establishments increased by only a modest 17 percent. It is a striking feature of the evolution of retail markets that over the last four decades of the twentieth century, the U.S. population increased by just over 100 million persons (or 56 percent), but the number of retail establishments serving them grew at a much slower rate. Figure 6.2 also shows how the composition of the increase in retail establishments is accounted for by single location establishments (mom-and-pop stores) and establishments owned by multiple location retailers (chain stores). The figure shows that the number of single location retail establishments actually decreases slightly over the

1. We use a SIC definition of the retail sector in this chapter. The Census Bureau adopted NAICS in 1997, but maintained SIC codes on its business register until 2001. Given difficulties in reclassifying all historic retail establishment data in the LBD on the North American Industry Classification System (NAICS) basis (see Bayard and Klimek 2004), we decided to use SIC definitions. 


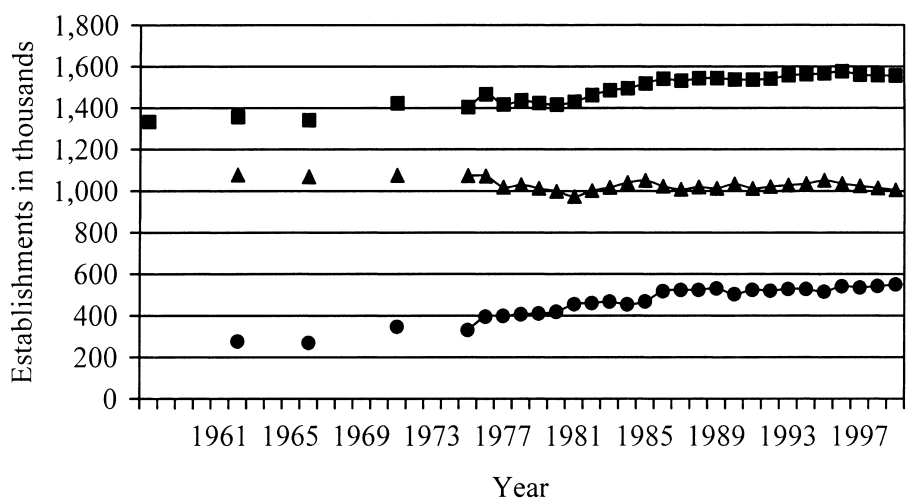

$\rightarrow$ Total Establishments $\rightarrow$ Single Location Establishments $\bullet \bullet$ Chain Establishments

Fig. 6.2 Number of retail establishments

Sources: Statistical abstract of the U.S. and own calculations from the LBD.

period while the number of chain store locations more than doubles. Retail establishments operated by multiple location chain retail firms accounted for 20.2 percent of all retail establishments in 1963 and increased to 35 percent by 2000 .

The ascendancy of chain stores is clearly one of the most important developments in the evolution of retail markets in the United States. Chain stores differ in many ways from the single location mom-and-pop stores that once dominated retail. This has always been the case, but it has become more important over time. Figure 6.3 shows that until around 1980 single location retailers and chains had roughly equal shares of overall retail sector employment. Since 1980, the chain store share of employment has increased to almost two-thirds of total retail employment. Contrast this with figure 6.2, which shows that chain stores make up a relatively constant one-third of all retail establishments. Between 1976 and 2000, employment at single location retailers grew by roughly 2 million workers. Employment growth at the smaller number of chain store retailers, on the other hand, was slightly under 8 million. Thus, we see that all the growth in the number of retail outlets and most of the growth in retail employment has come from retail firms that operate multiple retail establishments.

An obvious consequence of the faster growth of retail employment compared to retail establishments is that the average size of retail establishments has grown substantially over time. Figure 6.4 shows that the size of the average retail establishment has more than doubled between 1958 and 2000. Retail customers today are not shopping at the same kind of stores that existed forty years ago. They are far more likely to be patronizing large chain stores. Even the nature of the small single location, mom-and-pop 


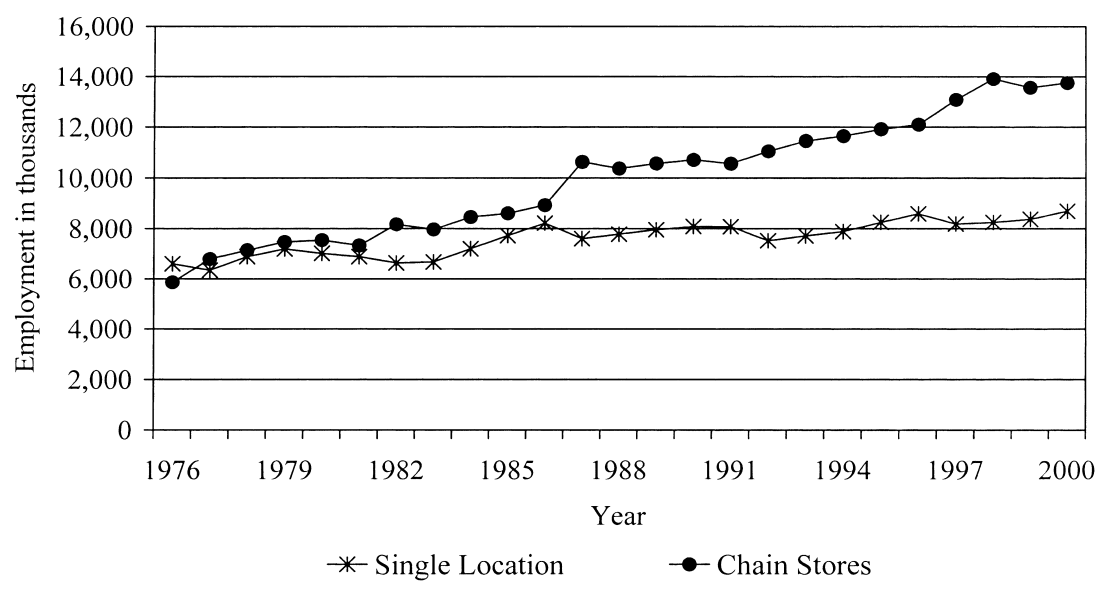

Fig. 6.3 Retail employment at single location and chain stores

Source: Own calculations from the LBD.

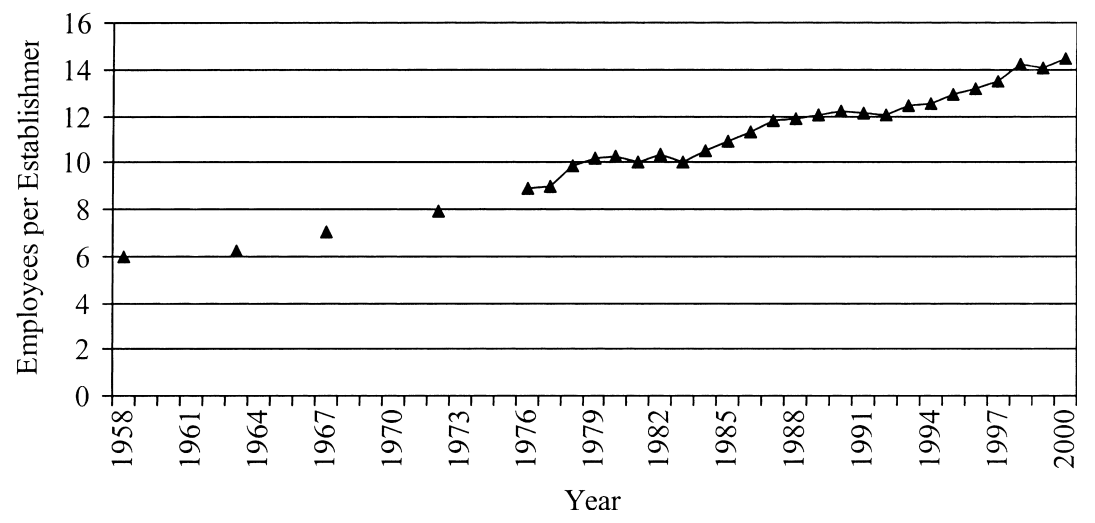

Fig. 6.4 Average retail establishment size

Source: Statistical Abstract of the U.S. and own calculations from the LBD.

stores has changed. In results discussed further in section 6.4, we see that single location retail firms have on average increased in size since 1976. This may be due to technological changes that increase optimal store sizes, or competitive pressure exerted by the growth of large chain retailers.

\subsubsection{Analyses of the Evolution of Retail Markets}

Researchers have developed both theoretical and empirical models that attempt to explain many of the features of retail markets. However, researchers have been hampered by a lack of detailed and comprehensive data to produce a set of stylized facts about the structure of the retail sec- 
tor. We hope that data sets such as the LBD will provide the tools researchers need to make more progress.

The feature of retail markets that attracts the most attention in the academic literature is the emergence of dominant chain firms. Bagwell, Ramey, and Spulber (1997) show how firms can come to dominate retail markets through large investments in cost reduction and vigorous price competition. Holmes (2001) explains how investments in information technology can lead to lower inventories, more frequent deliveries, and larger store sizes. Doms, Jarmin, and Klimek (2004) estimate the impact of investments in information technology on retail firm performance. They find that large firms account for nearly all the investment in IT in the retail sector and that IT improves the productivity of large firms more than it does for small firms.

However, as shown in the previous section, modern retail markets are marked by the simultaneous presence of large chain stores and small momand-pops. While the relative importance of the two classes of retailers has changed significantly over time, the chains have not yet driven out all the mom-and-pops. Dinlersoz (2004) and Ellickson (2005) have models that explain the simultaneous presence of dominant and fringe retailers. Basically, they view retail markets as segmented between large chain firms that invest in sunk costs, such as advertising, and small mom-and-pops that do not, but instead offer other retail attributes, such as better customer service. These models predict that the number of chains operating in retail markets increases less than proportionately to increases in market size, and that the number of single location mom-and-pops grows roughly proportionately. Put differently, the average size of chain stores grows with market size and the average size of mom-and-pops does not. Also, Campbell and Hopenhayn (2005) show that models where margins decline with additional entry can explain observed market structures where the number of retailers decline with market size.

Several observers have noted the important link between structural change in the retail sector and productivity growth. Sieling, Friedman, and Dumas (2001) and McKinsey (2002) both note that competitive pressure from technology-intensive chain stores such as Wal-Mart leads to productivity growth in the sector both by displacing less efficient retailers and by stimulating productivity improvement at surviving retail firms. Foster, Haltiwanger, and Krizan (2006) use economic census data to decompose changes in aggregate productivity. They show that net entry accounts for nearly all the productivity growth in the retail sector. The entry of establishments owned by chains is especially important as they are typically more productive than even the surviving incumbents.

In a detailed analysis of the displacement of existing establishments induced by the entry of a Wal-Mart, Basker (2005) shows that in the short run, Wal-Mart entry boosts county retail employment by several hundred. 
She uses a data set of the entry of Wal-Marts into counties, and uses publicly available County Business Patterns (CBP) data to examine the ex post change in the employment and number of producers. Although the short run impact is positive, county retail employment eventually falls as smaller retailers exit the market. The end result is that retail employment is actually larger (by about fifty jobs) than it was prior to Wal-Mart entering the county, while the number of establishments falls. However, she also finds an adverse affect on the wholesale sector, which loses about twenty jobs.

Many of the empirical findings for retail are limited by the quality of available data. Campbell and Hopenhayn (2005) and Basker (2005), for example, both use publicly available CBP data. These data are annual with a long time series, but cannot be used to measure the dynamics other than the net entry of establishments and firms. Other studies are limited to particular states or industries. Most do not have the industry coverage and detailed geography to describe changes in local retail markets. The goal of this chapter is to use the rich establishment-level microdata contained in the LBD to construct a set of stylized facts about the dynamics of the retail sector. The data allow us to examine results for the national and county markets, different categories of firms, establishments and firms, urban and rural counties, across different industries for the universe of retailers with paid employees. Even though much of our analysis does not use microdata, most of our measures could not be constructed without it.

\subsection{Data and Measurement Issues}

The discussion in the previous section helps us consider the data requirements for analyzing the dynamic structure of retail markets. The concept of producer dynamics as described in economics textbooks is pretty straightforward. Producer dynamics capture the entry and exit of sellers in an abstract market for a good or service. Theoretical models describing the behavior of buyers and sellers in various market settings show that the structure (e.g., the number and/or size distribution of sellers) and the presence (or absence) of barriers to entry (e.g., sunk costs) are important factors in determining how efficiently markets operate. In this context it is critical we understand what defines a market.

The theoretical literature abstracts away from the definition of a market, but this definition is at the very heart of empirical work. Empirical analyses of markets ideally require data at the firm-product level where product refers to some bundle of characteristics that would include price, location, and other product characteristics. However, such detailed data are rarely available. Thus, most empirical analyses of producer dynamics do not precisely measure the concepts that are so important for understanding market outcomes. The detailed geographic codes and firm ownership information in the LBD allows us to consider some of these issues. 


\subsubsection{Using the Longitudinal Business Database to Study the Evolution of Retail Markets}

The Census Bureau's Longitudinal Business Database (LBD) ${ }^{2}$ is being developed by CES as part of its mandate to construct, maintain, and use longitudinal research data sets. While falling short of the ideal dataset, several unique features of the LBD make it a powerful tool for studying producer dynamics and the evolution of retail markets. These include:

- Establishment (store) level data for the universe of retailers with paid employees

- Information for each establishment on the following:

- Longitudinal linkages

- Firm affiliation (i.e., firm structure and ownership changes)

- Location

- Year of birth (provides age for continuers)

- Year of death

- Detailed industry codes (SIC and/or NAICS)

- Size (based on payroll and employment)

- The LBD can be linked to Economic Census and survey data at the establishment and firm levels to provide more detailed data on inputs and outputs not available from administrative sources.

- Long time series

These features allow researchers to flexibly define markets and track changes in their structure over time. Linked to data on demand conditions and other unique features of particular markets, the LBD can be an extremely useful tool to researchers interested in producer dynamics.

Following we discuss how we use these features of the LBD to examine the evolution of retail markets. We also point out remaining data gaps and measurement issues. First we provide a brief description of the basic features of the LBD.

The LBD is based on the Census Bureau's Business Register (BR $)^{3}$ and contains longitudinally linked establishment data for all sectors of the economy. Currently, it covers the period between 1975 and 2001. For this chapter, the main advantage is that longitudinally linked data are available annually for all retail establishments in the United States. The quality of these links is critical to constructing accurate measures of establishment entry and exit, so a few additional points about its construction are useful (a detailed description can be found in Jarmin and Miranda [2002]).

2. The LBD contains confidential data under Titles 13 and 26 United States Code (U.S.C.). However, it can be accessed by researchers with approved projects at Census Bureau Research Data Center (RDC). Information on accessing these and other confidential Census Bureau microdata can be found at www.ces.census.gov

3. Formerly known as the Standard Statistical Establishment List (SSEL). 
The LBD is created by linking annual snapshots of the BR files. For this purpose the BR contains a number of numeric establishment and firm identifiers that can be used to track establishments over time. In particular, the Permanent Plant Number (PPN) was introduced in 1981 to facilitate longitudinal analysis. It is the only numeric establishment identifier on the $\mathrm{BR}$ that remains fixed as long as the establishment remains in business at the same location. However, research using the Longitudinal Research Database (LRD) - a manufacturing sector precursor to the LBD — showed that there are breaks in PPN linkages leading to spurious establishment births and deaths. Other numeric identifiers can change over time with various changes in the status of an establishment (e.g., ownership changes). For these reasons, name and address matching was used to augment the numeric identifiers to create the longitudinal linkages for the LBD. Successive years of the BR were first linked using numeric identifiers. The matches (i.e., numerically identified continuers) were set aside and the residuals were submitted to name and address matching using sophisticated statistical record linkage software. The improved establishment level identifier allows us to create the most accurate measures of establishment entry and exit for any Census Bureau data set.

Establishment and firm identifiers in the LBD combined with precise location information allow us to examine the entry and exit behavior of firms and establishments within specific geographic markets. The length and frequency are especially useful for these purposes, particularly for a sector as dynamic as retail trade. No other data source provides annual coverage for the universe of employer establishments and firms for as long a period as the LBD. Other data sources share some, but not all, of these characteristics.

For example, the Census of Retail Trade also covers the universe of establishments, but only occurs every five years. This implies that entry and exit of retail establishments and firms between Census years would be missed. The Annual and Monthly Surveys of Retail Trade occur more frequently, allowing the measurement of changes at the annual or even monthly level, but these data only collect information from a relatively small sample of firms. This means that we no longer have universal coverage of the sector, and the entry and exit of nonsampled firms would be missed. The Bureau of Labor Statistics (BLS) also has a longitudinally linked version of their business register, but they only have information for a taxpaying unit within a state. This means that the BLS data could not be used to address questions about the role of regional or national firms, as we discuss in the following section.

Finally, it is important to stress that the LBD gives us the ability to match establishments with their parent firm. This allows us to analyze both establishment-and firm-based measures of market structure. The relationship between the two measures is not obvious. On the one hand, firm dynamics omit relevant information regarding the entry and exit of estab- 
lishments, as firms already producing in the market expand the number of establishments in the market. This information is vital to understanding how firms expand their operations. On the other hand, establishment dynamics will miss vital information on the ownership and control of establishments, which may be an important determinant of establishment behavior. Given the very different nature of these alternative measures and the implications on aggregate statistics, we compute statistics for both establishments and firms.

\subsubsection{Measurement Strategy and Issues}

The ability to identify retail firms and to locate them in specific geographic markets is critical to our study. Firms are not homogeneous entities; some firms are large, have more resources, and may have experience in multiple markets. These differences are likely to drive differences in firm behavior and outcomes. Along these lines, there has been much popular attention regarding the displacement of small mom-and-pop stores by large national chains. In this section, we describe measurement issues related to our identification of firms and the markets in which they operate.

We use the information in the LBD to identify and distinguish between four types of retail firms in much of the analysis that follows. Our classification is based on the number of states a firm operates in similar to Foster, Haltiwanger, and Krizan (2006). First, single store retailers are defined as one type, which we also consider to be representative of mom-and-pop stores. Second, we classify multi-unit firms into three types of chain firms: local, regional, and national. A firm is a local chain if it operates multiple establishments in only one state. A firm is a regional chain if it operates in at least two states but no more than ten states. Finally, a firm is a national chain if it operates in more than ten states. ${ }^{4}$

We use detailed information in the LBD to analyze the changes taking place in small geographic areas. This apparently simple task presents us with several challenges. Ideally we would like to define markets based on some measure of the geographic clustering of retailers and the population that they serve. However, county is the smallest reliable geographic unit of analysis that is available in the LBD. Coding to finer levels is less of a priority for the Census Bureau since few economic statistics are published for geographic units smaller than the county level, and as a result these measures are not as reliable. ${ }^{5}$ With these constraints we define local markets

4. We also explored an alternate definition using a measure of distance for all establishments within a firm. We find that this measure does differ somewhat from a number of states based definition. We decide to stay with the literature.

5. Depending on the availability and quality of a physical street address, the Census Bureau can, and does, assign more detailed geography codes. Depending on the year, between 60 and 75 percent of establishments have Census Block and Tract codes. In Jarmin and Miranda (forthcoming), we have assigned many of these establishments latitude and longitude coordinates. 
based on the administrative definition of a county. This has both advantages and disadvantages. On the one hand, defining local markets in this fashion is clearly arbitrary. A local retail market can encompass multiple counties, particularly in metropolitan areas. At the same time one county can encompass multiple local markets, as is often the case in physically large or densely populated counties.

On the other hand, even though the county unit is a relatively crude way to define retail markets, an advantage is that there is a large amount of county level information (e.g., population) that researchers have available to control for market characteristics. One market characteristic that receives a lot of attention in the literature is size. We have a wide variety of options available in measuring the size of a county market. For this chapter, we use a parsimonious and accessible measure of market size. In addition, for the statistics we generate and report, we do not want individual counties to change market type over the period under study. Thus, we classify counties as metropolitan, micropolitan, or rural based on their 2000 Core Base Statistical Area (CBSA) code. ${ }^{6}$

Even at this crude level of geography we find that about 4 percent of establishments in the LBD have inconsistent county codes. Census assigns these codes every year based on their physical or mail address. As a consequence it is not unusual in our data to see establishments that border county lines switching back and forth. This is primarily an artifact of updates to the census files that map street names to counties. In our empirical analysis, we assign a unique county code to establishments observed switching county codes. ${ }^{7} \mathrm{We}$ assign the county coded during the latest census year when possible; otherwise, we assign the modal county for the establishment. Our eventual goal is to use variation in many dimensions at the county level to control for differences in market characteristics including demographic composition, population density, tax structure, communications infrastructure, and proximity to other population centers.

There are 1,083 counties classified as metropolitan areas, 682 counties classified as micropolitan areas, and 1,336 counties classified as nonmetro areas based on CBSA codes. We refer to these nonmetro areas as rural areas. We exclude from our computations the states of Alaska and Hawaii as well as outlying U.S. territories. Table 6.1 shows that most of the 2000 U.S. population of individuals and firms is located in metropolitan areas. Approximately 17.3 percent of the population of individuals and 13.5 percent of the population of establishments is located in rural or micropolitan areas. On average, rural areas are less than 7 percent the size (in popula-

6. Detailed information on these new geographic definitions can be found in Office of Management and Budget (2000).

7. Miranda (2001) documents that approximately 4 percent of establishments show changes in county codes. 
Table 6.1

U.S. Retail markets by CBSA and rural areas in 2000

\begin{tabular}{lrrrrrr}
\hline & Counties & Population & Firms & Establishments & Employment & Payroll \\
\hline & & & \multicolumn{2}{c}{ Totals by market type } \\
Metro & 1,083 & $229,783,293$ & 961,264 & $1,223,079$ & $18,660,642$ & $319,571,179$ \\
Micro & 682 & $29,023,781$ & 159,969 & 176,701 & $2,187,425$ & $31,296,137$ \\
Rural & 1,336 & $19,229,414$ & 120,242 & 129,161 & $1,256,810$ & $17,625,669$ \\
& & \multicolumn{7}{c}{ Averages by } & market type & \\
Metro & 212,173 & 888 & 1,129 & 17,231 & 295,080 \\
Micro & 42,619 & 235 & 259 & 3,212 & 45,956 \\
Rural & 14,404 & 90 & 96 & 939 & 13,163 \\
\hline
\end{tabular}

Source: Own calculations from the LBD.

Note: This number represents the number of firms operating in a CBSA type. Chain firms can operate in counties of, potentially, all three types. Thus, there is double counting of firms in the table. The number of retail firms operating in the U.S. in 2000 was 1,066,510.

tion terms) of metropolitan areas. The average micropolitan area is about 20 percent the size of the average metropolitan area.

The decision to open (or close) an establishment in a particular market is made at the firm level. In this sense, the ability to identify firm dynamics in small geographic areas is critical for understanding firm behavior as well as their response to market changes. The detailed establishment-level data in the LBD allow us to identify when a firm first enters a county, when it exits a county, and whether it has a presence in other county markets. We can also identify firm expansions or contractions in a particular market, and whether it does so by adjusting employment at existing establishments or by adjusting the number of establishments.

Note that as a result of our focus on local markets, a firm can be an entrant simultaneously into multiple markets and also account for one or more market exits in different locations. Similarly, an establishment entry is not necessarily a firm entry if the firm was already present in that market. Finally, the closure of an establishment does not necessarily generate a firm exit if the firm remains operational in the county.

In the chapter we restrict our analysis to retail firms. The quality of the industry codes available on the LBD is critical to the construction of a retail sector micro data set. New establishments, especially those that begin operations between census years (i.e., those ending in two or seven) often have missing or poor quality industry codes. Between 1 percent and 10 percent of records have missing codes in the BR depending on the year and whether it is a single-unit or multi-unit establishment. Valid and improved codes are eventually obtained from direct Census Bureau collections or other sources and incorporated into the BR. These clean-up activities are concentrated in particular years, usually in preparation for an economic 
census. To maximize the quality of industry codes on the LBD, we choose the best code available for each establishment and take advantage of codes obtained from various sources and at different times. In particular, we use census or survey collected data whenever possible, but we may use an administrative code if no other data is available. ${ }^{8}$

Industry codes are subject to change for particular establishments over time. This occurs for about 4.5 percent of the establishments classified as retail at some point in their operational existence. There are two possible reasons for this. First, establishment may legitimately decide to change its type of activity. Second, errors in the data are possible. We address both issues by assigning each establishment in our data a unique two-digit SIC that remains fixed over the establishment's entire history. When possible, we use industry codes collected in surveys or the economic census for the unique SIC. Alternatively, we assign the unique SIC using the most recent SIC available on the file. A current limitation of the LBD is that it is based primarily on a SIC basis. From 1976 to 1996, the SIC industry codes were the basis for all Census Bureau publications. From 1997 onward, data have been published on a NAICS basis. The Census Bureau continued to maintain SIC industry codes on the BR through 2001. Since 2002, the Census Bureau maintains only NAICS industry codes on the BR, resulting in a potential time series break in the LBD data. In addition, it is possible that the quality of the SIC codes declined between 1998 and 2001.

The LBD contains information on two important measures of establishment size, payroll and employment. Revenue information contained in the BR is not currently on the LBD since it is only available for single-unit firms and at the employer identification number (EIN) level for multi-unit firms. While payroll and employment are clearly two important measures of economic activity at the establishment, they only measure inputs to retail production. Success or failure of an establishment or firm should depend on profits. This means that researchers wishing to use detailed data on establishment and firm profits (or productivity) must rely on Census Bureau censuses and surveys.

Finally, the LBD covers a relatively long period. It extends back to 1975 , and covers the recessions of the early 1980s and early 1990s and spans a period of significant technical change and innovation. However, this may not be long enough to actually witness much of the structural change in the retail sector. As figure 6.3 shows, employment by chain stores surpassed that of single-establishment firms in 1977. It is likely that in order to observe the long run changes in the retail sector we would need a data set that extended

8. Industry codes are obtained from multiple sources and these can change depending on the year. The most reliable code is obtained from survey forms in Census years. Other sources include administrative data from the Internal Revenue Service (IRS), Social Security Administration (SSA), and the Bureau of Labor Statistics (BLS). 
back to the 1940s or 1950s, when we would expect to find relatively few chain stores and the dominance of mom-and-pop stores. As we show in the following section, different types of geographic markets might be at different stages in this process, and we focus on the long run differences from 1976 to 2000.

\subsection{Results}

In an average year, there are over 1.4 million retail establishments associated with over 1 million firms. The database used in this section consists of all retail establishments from 1976 to 2000. Data elements available for the period include industry, geography, payroll, and employment. In 2000, these firms employed more than 22 million workers and generated over $\$ 368.5$ billion in payroll. The section is organized in the following manner. First, we examine the trends in the national market for our four types of firms: mom-and-pops, and local, regional, and national chains. Next, we look at similar patterns, but disaggregated by the three types of county markets: metropolitan, micropolitan, and rural. Finally, we summarize the results at the two-digit SIC industry level.

\subsubsection{National Market, by Type of Firm}

In this subsection, we analyze some basic trends in the structure of retail markets averaged across all county markets. We first look at trends in the number and size of retail establishments (i.e., stores) by retail firm type. We then look at the basic establishment entry and exit statistics, also by retail firm type.

\section{Basic Results on Retail Market Structure: Trends in the Number of Size of Retail Establishments}

Figure 6.5 shows the mean number of retail establishments per 1,000 county residents over the 1976 to 2000 period broken out by the four types of firms. Overall, the mean number of retail establishments drops from 7.44 to 5.88 establishments for all counties. The only type of firm that experiences a decline in the number of establishments per capita over the period is the mom-and-pops. The number of mom-and-pop stores falls from 6.2 to 4.25 stores (or 31.4 percent) during this period. All three types of chains see the number of establishments increase during this period. Overall, chain stores increase from 1.32 to 1.76 establishments, or a 36.6 percent increase. On average, the composition of firm types in these markets is shifting from mom-and-pops to chains.

Figure 6.6 combines the number of establishments and employment data to examine the shift in establishment size within these types of firms. We find that all types of firms grow on average, even the mom-and-pop stores. Mom-and-pops grow on average since their employment remains 




$\square$ Single Unit $\triangle$ Local Chain $\diamond$ Regional Chain $\longrightarrow$ National Chain $\bullet$ Total Chain

Fig. 6.5 Mean number of establishments per 1,000 residents-all counties Source: Own calculations from the LBD.

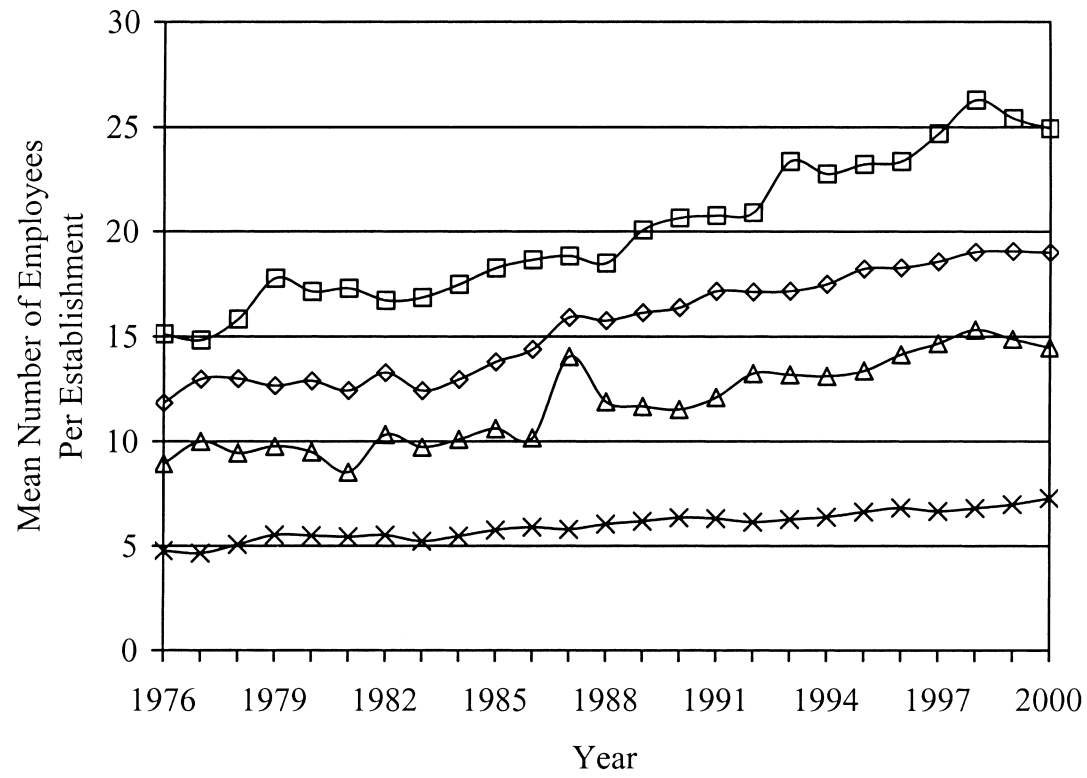

$\star$ Single Unit $\triangle$ Local Chain $\diamond$ Regional Chain $\square$ National Chain

Fig. 6.6 Mean establishment size by firm type-all counties Source: Own calculations from the LBD. 
relatively constant, but the number of establishments on average declines during this period. However, they only grow from about five employees to about seven employees. We find that firms of all types have larger store sizes during this period, with the largest increase coming from national chains. Local chain stores increase employment from roughly nine to fifteen employees, regional chains from roughly twelve to nineteen, and national chains from roughly fifteen to twenty-five.

\section{Basic Results on Retail Market Structure: Establishment Entry and Exit}

The firm entry, exit, and continuer rates in tables 6.2, 6.4, and 6.5 are defined as in Dunne, Roberts, and Samuelson (1988). We define $\mathrm{N}_{f t-1}$ as the number of establishments owned by retail firms of type $f$ in period $t-1, \mathrm{X}_{f t}$ as the number of establishments owned by firms of type $f$ that were active in period $t-1$ but are no longer active in period $t$, and $\mathrm{E}_{f t}$ as the number of establishments owned by firms of type $f$ that were not active in period $t-1$, but are active in period $t$. Finally, we define $\mathrm{C}_{f t}$ as the number of establishments owned by firms of type $f$ that were active in both period $t-1$ and $t$. Entry, exit and continuer rates are:

$$
\begin{array}{ll}
\text { Entry Rate: } & \mathrm{ER}_{f t}=\mathrm{E}_{f t} / \mathrm{N}_{f t-1}, \\
\text { Exit Rate: } & \mathrm{XR}_{f t}=\mathrm{X}_{f t} / \mathrm{N}_{f t-1} \\
\text { Continuer Rate: } & \mathrm{CR}_{f t}=\mathrm{C}_{f t} / \mathrm{N}_{f t-1} .
\end{array}
$$

where $f$ is in \{single-unit, local chain, regional chain, national chain\}. All rates are relative to the number of firms operating in the prior period, implying that XR $+\mathrm{CR}=1$ for each type of firm. We can also weight by employment to construct the entrant, exit, and continuer employment share. ${ }^{9}$

Table 6.2 reports these rates averaged across all years by retail firm type. The top panel shows unweighted entry, exit, and continuer rates. Recall that figure 6.5 shows a relatively large decline in the number of single-unit establishments per capita and slight increases in the number of establishments per capita for chains. The top panel of table 6.2 confirms that single location firms have higher rates of exit than entry and, thus, on average experience net exit each year. As we move to the different types of chains, the larger the chain, the lower the rates of both entry and exit (except for a slightly higher entry rate for regional chains). The overall effect is that net entry (ER-XR) is positive for all types of chains, and larger chains have higher rates of net entry.

In the bottom panel of table 6.2, we present entry, exit, and continuer

9. In Dunne, Roberts, and Samuelson (1988), the entrant share of employment (ESH) is divided by the period $t$ employment, but in this chapter we divide by period $t+1$ employment. The exit share of employment (XSH) is constructed the same way, dividing by the period $t$ employment. 
Table 6.2

Establishment entry and exit rates for the U.S. retail sector (National rates averaged across all years, 1976-2000)

\begin{tabular}{lcccc}
\hline & Single & Local & Regional & National \\
\hline Unweighted & & & & \\
$\quad$ Entry Rate (ER) & 0.149 & 0.092 & 0.093 & 0.088 \\
$\quad$ Exit Rate (XR) & 0.151 & 0.085 & 0.076 & 0.069 \\
$\quad$ Continuer Rate (CR) & 0.849 & 0.915 & 0.924 & 0.931 \\
Weighted by employment & & & & \\
$\quad$ Entrant Share (ESH) & 0.078 & 0.078 & 0.065 & 0.055 \\
$\quad$ Exit Share (XSH) & 0.108 & 0.056 & 0.046 & 0.043 \\
Continuer Share (CSH) & 0.892 & 0.944 & 0.954 & 0.957 \\
\hline
\end{tabular}

Source: The LBD.

rates weighted by employment. Across all firm types, entrants and exits tend to be smaller than continuing firms, thus the weighted entry and exit rates are lower than their unweighted counterparts. The results on employment-weighted shares show that the net entry of employment for chains is actually highest for local, regional, and then national chains on average during the period.

\subsubsection{Results by Market and Firm Type}

In the previous section, we examined the national retail market; however, we have already shown that there are considerable differences across county types. In this section, we examine changes in market structure and dynamics across the three county market types and by firm type. We start by summarizing the changing nature of the distribution of the number of retail establishments and firms operating in county markets and retail employment by county type. We then look at firm entry into and exit from these county markets by county type. We focus on firm entry since the firm is the relevant decision maker in the market.

Table 6.3 describes the distribution of establishments, firms, and employment per capita. It reports the mean number of establishments, firms, and employees per 1,000 county residents within each county type for both 1976 and 2000. We also report the standard deviation to provide a sense of the variation across counties within each type of county.

We see a number of important differences between the three types of county markets. At the beginning of the period, rural counties have on average two more establishments per capita than do metropolitan counties, but they also have two more firms and nine fewer employees per capita. This implies that we observe a larger number (on a per capita basis) of smaller firms in rural areas. Micropolitan counties also have more establishments and firms per capita than metropolitan counties, but not as many as rural counties. In terms of employment, micropolitan and metropolitan 
County retail market structure: Number of establishments, firms, and employees by market type (based on per capita county level aggregates)

\begin{tabular}{|c|c|c|c|c|c|c|c|}
\hline \multirow[b]{2}{*}{ Year } & \multirow{2}{*}{$\begin{array}{l}\text { Market } \\
\text { Type }\end{array}$} & \multicolumn{3}{|c|}{ Mean } & \multicolumn{3}{|c|}{ Standard deviation } \\
\hline & & Establishments & Firms & Employment & Establishments & Firms & Employment \\
\hline 1976 & Metro & 6.3 & 5.8 & 47.8 & 1.9 & 1.8 & 25.5 \\
\hline 1976 & Micro & 7.5 & 7.2 & 48.4 & 2.0 & 1.9 & 18.6 \\
\hline 1976 & Rural & 8.3 & 8.1 & 38.2 & 2.8 & 2.8 & 18.1 \\
\hline 2000 & Metro & 5.2 & 4.5 & 70.9 & 1.9 & 1.7 & 37.6 \\
\hline 2000 & Micro & 6.0 & 5.6 & 71.2 & 2.0 & 1.8 & 28.2 \\
\hline 2000 & Rural & 6.4 & 6.1 & 52.7 & 2.9 & 2.9 & 28.2 \\
\hline
\end{tabular}

Source: The LBD.

counties have roughly the same number of retail employees per capita. From 1976 to 2000, there is a significant decline in the number of establishments and firms in all types of county markets. At the same time, we observe a significant increase in the retail employment across all types of counties. Metropolitan and micropolitan counties continue to have roughly the same levels of retail employment, and rural counties are still significantly smaller. The overall effect is that the average size of an establishment has grown in each type of region. Finally, we see that the variance of the establishment and firm distributions did not change over time, but that the variance of the employment distribution increased over the period from 1976 to 2000 .

In table 6.4, we present average firm entry, exit, and continuer rates by metropolitan, micropolitan, and rural county types. As in table 6.2, we show the annual rates averaged over the entire period of 1976 to 2000. Like the results for establishments in table 6.2, we see that single-unit firms have higher entry and exit rate across all market types. Local chains have slightly higher rates of entry and exit than do regional and national chains. Table 6.4 shows only small differences between regional and national chains.

Table 6.4 reveals that average net entry rates for single-unit retailers are negative for all market types. This is similar to figure 6.5 , which showed the drop in the average number of single-unit establishments per capita across all counties. In contrast, net entry rates are nonnegative for chain retailers.

Firm turnover rates are computed as the sum of the entry and exit rates $(\mathrm{ER}+\mathrm{XR})$. These are a measure of churning within retail markets. We see from table 6.4 that single-unit retailers experience more churning that do chain stores. More interesting perhaps is the finding that turnover rates increase with market size. Metropolitan counties, in particular, experience more turnover across all types of retail firms than do micropolitan or rural markets. The difference in retail firm turnover between metropolitan and rural county market types is $0.006,0.017,0.038$, and 0.019 for single units, 
Table 6.4

Firm entry and exit rates for the U.S. retail sector (Rates by market type averaged across all years, 1976-2000)

\begin{tabular}{lcccc}
\hline & Single & Local & Regional & National \\
\hline Entry Rate (ER) & & & & \\
$\quad$ Rural & 0.143 & 0.085 & 0.077 & 0.077 \\
$\quad$ Micro & 0.144 & 0.087 & 0.082 & 0.077 \\
$\quad$ Metro & 0.151 & 0.094 & 0.097 & 0.089 \\
Exit Rate (XR) & & & & \\
$\quad$ Rural & 0.153 & 0.078 & 0.061 & 0.064 \\
$\quad$ Micro & 0.150 & 0.077 & 0.065 & 0.063 \\
$\quad$ Metro & 0.151 & 0.087 & 0.079 & 0.070 \\
Continuer Rate (CR) & & & & \\
$\quad$ Rural & 0.847 & 0.922 & 0.939 & 0.936 \\
$\quad$ Micro & 0.850 & 0.923 & 0.935 & 0.937 \\
$\quad$ Metro & 0.849 & 0.913 & 0.921 & 0.930 \\
\hline
\end{tabular}

Source: The LBD.

local, regional, and national retail chains, respectively. Thus, we see that large metropolitan retail markets are characterized by fewer competitors per capita than rural and micropolitan county markets, but that competition in metropolitan markets is marked by higher firm turnover, and that this higher turnover is more pronounced among chain store retailers. Further, our firm turnover measure may understate the degree of volatility in county markets since retail chains can change their scale of activity in county markets by opening or closing stores. Our measure does not capture when firms expand or contract the number of stores in a county, as long as they continue to operate at least one store in the county.

Table 6.5 shows employment-weighted entry, exit, and continuer rates. As before, we see that entrants and deaths tend to be smaller than continuing firms as reflected by the lower weighted entry and exit rates. This result is true across market types. Also note the net gain in employment from entry and exit of retail stores across market types for all retail chains. This is not the case for mom-and-pops, which show the highest losses in metropolitan areas.

\subsubsection{Industry Differences}

In this section, we look at differences in producer dynamics and the role of chain stores across two-digit retail industries. First, we compare the number of county markets served by the four firm types in 1977 and 2000. We are trying to understand how the role of these firm types within county retail markets has changed over time and determine if there are systematic differences in these changes across different retail industries. The results of this exercise are reported in table 6.6.

One important thing to note in table 6.6 is that many county markets are 
not served by all retail firm types. Expectedly, most of the 3,101 U.S. counties (excluding Alaska and Hawaii), are served by single-unit firms in most two-digit SIC retail industries. However, the situation is quite different when looking at the different chain types. Indeed, it is often the case that the majority of U.S. counties are not served by one or more chain types within these broad two-digit SIC industries. From table 6.1 we know that rural counties are the dominant county market type numerically, are quite small, and may not offer sufficient demand to justify the scale of many

Table 6.5 Employment-weighted firm entry and exit rates for the U.S. retail sector (Mean by market type, 1976-2000)

\begin{tabular}{lcccc}
\hline & Single & Local & Regional & National \\
\hline Entrant Share (ESH) & & & & \\
$\quad$ Rural & 0.078 & 0.072 & 0.055 & 0.060 \\
$\quad$ Micro & 0.078 & 0.078 & 0.058 & 0.051 \\
$\quad$ Metro & 0.078 & 0.078 & 0.067 & 0.055 \\
Exit Share (XSH) & & & & \\
$\quad$ Rural & 0.107 & 0.053 & 0.039 & 0.040 \\
$\quad$ Micro & 0.107 & 0.052 & 0.040 & 0.040 \\
$\quad$ Metro & 0.109 & 0.057 & 0.047 & 0.043 \\
Continuer Share (CSH) & & & & \\
$\quad$ Rural & 0.893 & 0.947 & 0.961 & 0.960 \\
$\quad$ Micro & 0.893 & 0.949 & 0.960 & 0.960 \\
$\quad$ Metro & 0.891 & 0.943 & 0.953 & 0.957 \\
\hline
\end{tabular}

Source: The LBD.

Table 6.6

Number of county markets served by different retail firm types (1977 and 2000, by two-digit SIC)

\begin{tabular}{|c|c|c|c|c|c|c|c|c|}
\hline \multirow[b]{2}{*}{$\mathrm{SIC}$} & \multicolumn{2}{|c|}{ Single } & \multicolumn{2}{|c|}{ Local } & \multicolumn{2}{|c|}{ Regional } & \multicolumn{2}{|c|}{ National } \\
\hline & 1977 & 2000 & 1977 & 2000 & 1977 & 2000 & 1977 & 2000 \\
\hline $\begin{array}{l}52 \text { Building Materials } \\
\text { and Hardware }\end{array}$ & 3,005 & 2,960 & 1,909 & 1,765 & 1,484 & 1,380 & 1,157 & 1,490 \\
\hline 53 General Merchandise & 2,835 & 2,138 & 1,485 & 629 & 1,886 & 843 & 2,087 & 2,673 \\
\hline 54 Food Stores & 3,089 & 3,072 & 2,327 & 2,352 & 1,891 & 2,277 & 1,770 & 1,806 \\
\hline $\begin{array}{l}55 \text { Auto Dealers and } \\
\text { Gas Stations } \\
56 \text { Apparel and }\end{array}$ & 3,096 & 3,066 & 2,441 & 2,504 & 1,954 & 2,407 & 1,770 & 2,039 \\
\hline Accessories & 2,904 & 2,518 & 1,865 & 1,092 & 1,544 & 1,180 & 1,852 & 1,763 \\
\hline $\begin{array}{l}57 \text { Home Furnishing } \\
\text { and Equipment } \\
58 \text { Eating and Drinking }\end{array}$ & 2,848 & 2,792 & 1,666 & 1,429 & 1,020 & 1,035 & 954 & 1,393 \\
\hline Places & 3,095 & 3,088 & 2,062 & 2,384 & 1,603 & 2,275 & 1,465 & 2,010 \\
\hline 59 Miscellaneous Retail & 3,067 & 3,060 & 2,480 & 2,224 & 1,631 & 1,804 & 2,101 & 2,204 \\
\hline
\end{tabular}

Source: The LBD. 
chain retailers. Nevertheless, some retailers such as Wal-Mart have declared intentions for substantial expansion of the next several years. ${ }^{10}$ It will be interesting to see whether chains will continue to expand into new markets.

The changes over the period in the number of county markets served by the different firm types are quite striking. We see that the number of counties served by at least one mom-and-pop retailer actually falls in every industry. The fall is not dramatic, but that fact that we observe a decline is surprising given the ubiquity of small retailers. On the other side, we find that the number of markets being served by a national chain is increasing for all industries and that some of the increases are dramatic. Results for local and regional chains vary across the different industries.

General Merchandise firms show a very interesting trend. As expected, given the rise of stores such as Wal-Mart and Target and the consolidation of once-regional department stores, we see that the number of county markets served by national retail chains has grown substantially over the period. This growth is accompanied by dramatic reductions in the number of markets served by single-unit, local chains, and regional chains of general merchandise firms.

The trends in the number of county markets served by the various firm types differ substantially across retail industries. In Eating and Drinking Places, there is only a small reduction in the number of markets served by single-unit producers and there are large increases in the number of markets served by all types of chains. Contrast that with the trends in Apparel and Accessories, where we see that the number of markets served by all firm types decreases as the industry shrinks.

While changes in the number of markets served by the different types of firms are interesting, we also focus on how entry and exit rates (establishment and firm) differ across industries. We construct a more detailed data set with entry and exit rates defined within the county, year, two-digit SIC, and chain type. While more detailed industries at the six-digit level are potentially available in the LBD, we already have a significant number of industries at the two-digit level where we cannot construct an entry or exit rate (since $\mathrm{N}_{f t-1}=0$ ). We mitigate this problem by computing entry and exit rates as in Davis, Haltiwanger, and Schuh (1996):

$$
\begin{aligned}
\mathrm{ER}_{f c t} & =\frac{\mathrm{E}_{f c t}}{\left[\left(\mathrm{~N}_{f c t}+\mathrm{N}_{f c t-1}\right) / 2\right]} \\
\mathrm{XR}_{f c t} & =\frac{\mathrm{X}_{f c t}}{\left[\left(\mathrm{~N}_{f c t}+\mathrm{N}_{f c t-1}\right) / 2\right]}
\end{aligned}
$$

10. Wal-Mart's 2005 annual report indicates that it plans to open 1,000 new supercenters in the United States over the next five years and Lee Scott, Wal-Mart's CEO says there is room in the United States for 4,000 more Wal-Mart supercenters. 
We summarize industry differences in entry and exit rates using a series of simple regressions. We include dummies for both firm and county market type. We also include a series of dummies for each five-year period from 1976 through 2000. The omitted group is mom-and-pop stores in rural markets during the period of 1996 to 2000.

We present entry rate results for both establishments and firms in table 6.7. Looking at the intercept terms, we see that the industry with the highest establishment and firm entry rates is SIC 58, Eating and Drinking Establishments (this still holds if one uses the other coefficients to calculate entry rates for chains in nonrural counties). The industry with the lowest establishment and firm entry rates is SIC 52, Building Materials and Hardware.

Table 6.7

Establishment and firm entry rate regressions

\begin{tabular}{|c|c|c|c|c|c|c|c|c|}
\hline $\mathrm{SIC}$ & 52 & 53 & 54 & 55 & 56 & 57 & 58 & 59 \\
\hline \multicolumn{9}{|c|}{ Panel A: Establishment entry rates } \\
\hline Intercept & 0.083 & 0.140 & 0.133 & 0.089 & 0.106 & 0.106 & 0.154 & 0.114 \\
\hline \multicolumn{9}{|l|}{ Time period } \\
\hline $1976-1980$ & 0.032 & -0.017 & 0.010 & 0.046 & 0.034 & 0.033 & 0.045 & 0.031 \\
\hline $1981-1985$ & 0.023 & -0.026 & 0.017 & 0.043 & 0.030 & 0.046 & 0.042 & 0.034 \\
\hline 1986-1990 & 0.007 & -0.013 & 0.000 & 0.022 & 0.026 & 0.026 & 0.030 & 0.018 \\
\hline 1991-1995 & -0.011 & -0.008 & -0.013 & 0.000 & 0.004 & 0.009 & 0.009 & 0.009 \\
\hline \multicolumn{9}{|l|}{ Market type } \\
\hline Metro & 0.024 & 0.017 & 0.021 & 0.010 & 0.022 & 0.018 & -0.003 & 0.013 \\
\hline Micro & 0.015 & 0.008 & 0.013 & 0.002 & 0.007 & -0.005 & -0.002 & 0.001 \\
\hline \multicolumn{9}{|l|}{ Firm type } \\
\hline National chain & -0.035 & -0.078 & -0.082 & -0.041 & -0.050 & -0.053 & -0.071 & -0.046 \\
\hline Regional chain & -0.040 & -0.073 & -0.090 & -0.022 & -0.038 & -0.034 & -0.068 & -0.038 \\
\hline Local chain & -0.047 & -0.073 & -0.075 & -0.029 & -0.063 & -0.052 & -0.059 & -0.062 \\
\hline \multicolumn{9}{|c|}{ Panel B: Firm entry rates } \\
\hline Intercept & 0.088 & 0.141 & 0.133 & 0.099 & 0.120 & 0.101 & 0.166 & 0.121 \\
\hline \multicolumn{9}{|l|}{ Time period } \\
\hline $1976-1980$ & 0.032 & -0.016 & 0.013 & 0.043 & 0.024 & 0.039 & 0.045 & 0.030 \\
\hline 1981-1985 & 0.024 & -0.010 & 0.024 & 0.041 & 0.020 & 0.048 & 0.041 & 0.037 \\
\hline 1986-1990 & 0.010 & 0.010 & 0.010 & 0.014 & 0.019 & 0.026 & 0.028 & 0.021 \\
\hline 1991-1995 & -0.012 & -0.006 & -0.008 & -0.006 & 0.002 & 0.007 & 0.007 & 0.009 \\
\hline \multicolumn{9}{|l|}{ Market type } \\
\hline Metro & 0.026 & 0.009 & 0.028 & 0.011 & 0.020 & 0.031 & -0.001 & 0.013 \\
\hline Micro & 0.014 & 0.005 & 0.009 & 0.004 & 0.008 & 0.007 & 0.001 & 0.004 \\
\hline \multicolumn{9}{|l|}{ Firm type } \\
\hline National chain & -0.030 & -0.091 & -0.074 & -0.029 & -0.054 & -0.029 & -0.072 & -0.031 \\
\hline Regional chain & -0.028 & -0.056 & -0.062 & -0.021 & -0.036 & -0.034 & -0.052 & -0.033 \\
\hline Local chain & -0.059 & -0.083 & -0.080 & -0.047 & -0.078 & -0.073 & -0.078 & -0.075 \\
\hline
\end{tabular}

Source: Own calculations from the LBD.

Notes: Unit of Observation is a \{county, year, firm type cell. Regressions are run by 2-digit SIC with controls for time period, market type, and firm type. All coefficients are significant at the 5 percent level. 
The pattern of estimated time period dummies generally show that entry rates are declining over time. We observe monotonic declines in the time period dummies in several industries. Only with SIC 53, General Merchandise Stores, do we observe a lower entry rate in the initial period than we do in the final period. This finding holds for both establishment and firm entry rates.

With the exception of Eating and Drinking Places, SIC 58, entry rates are highest in metropolitan markets and slightly higher in micropolitan markets. This is similar to results for the entire retail sector shown in table 6.4. We find mixed results for the chain type dummies. The negative coefficients imply that the mom-and-pop stores have the largest entry rates, regardless of industry or unit of measure (establishment or firm).

We find exit rate results for both establishments and firms similar to those for the entry rate. The results, presented in table 6.8, again show that SIC 58 has the highest establishment and firm exit rates and SIC 52 has the lowest. We also find that exit rates are declining over time, with the effect being monotonic in about half the industries. We generally find that exit rates are highest in metropolitan markets and slightly higher in micropolitan markets than in rural markets. We find mixed results for the different types of chains. The negative coefficients imply that the mom-and-pop stores have the largest exit rates, regardless of industry or unit of measure (establishment or firm). We also find that firm exit rates are next highest for regional chains for all industries, with no pattern for local and national chains across the industries. This pattern does not hold for establishment exit rates.

\subsection{Conclusion}

This chapter provides a rich set of stylized facts describing the evolution of U.S. retail markets over the last thirty years. We use the Longitudinal Business Database, which offers a long time series of longitudinal data covering all retail establishments with paid employees. Detailed information on establishment location and firm ownership allows us to examine changes in market structure and producer dynamics, focusing on the role of retail chains.

These data allow us to corroborate several important trends already described by other empirical work, as well as document some new findings. We document the steady ascendance of retail chains in terms of both their share of employment and establishments, as well as the decline of relatively small mom-and-pops. Customers shop at much larger stores today than they did thirty years ago. Interestingly, we find there are fewer establishments per 1,000 residents, but they are significantly larger. The absolute growth in the size of the national chain store is particularly striking in this regard. However, we also observe that single location mom-and-pop stores 
Table 6.8

Establishment and firm exit rate regressions

\begin{tabular}{|c|c|c|c|c|c|c|c|c|}
\hline $\mathrm{SIC}$ & 52 & 53 & 54 & 55 & 56 & 57 & 58 & 59 \\
\hline \multicolumn{9}{|c|}{ Panel A: Establishment exit rates } \\
\hline Intercept & 0.095 & 0.147 & 0.130 & 0.103 & 0.164 & 0.114 & 0.164 & 0.130 \\
\hline \multicolumn{9}{|l|}{ Time period } \\
\hline $1976-1980$ & 0.030 & 0.000 & 0.028 & 0.088 & -0.017 & 0.031 & 0.043 & 0.029 \\
\hline 1981-1985 & 0.015 & 0.004 & 0.016 & 0.046 & -0.022 & 0.019 & 0.022 & 0.010 \\
\hline $1986-1990$ & 0.006 & -0.005 & 0.014 & 0.028 & -0.021 & 0.002 & 0.011 & 0.000 \\
\hline $1991-1995$ & 0.003 & 0.003 & 0.005 & 0.004 & -0.003 & -0.003 & -0.003 & 0.000 \\
\hline \multicolumn{9}{|l|}{ Market type } \\
\hline Metro & 0.018 & 0.015 & 0.019 & 0.010 & 0.017 & 0.021 & -0.011 & 0.005 \\
\hline Micro & 0.008 & 0.006 & 0.009 & 0.002 & 0.006 & 0.002 & -0.006 & -0.001 \\
\hline \multicolumn{9}{|l|}{ Firm type } \\
\hline National chain & -0.072 & -0.114 & -0.084 & -0.067 & -0.098 & -0.082 & -0.083 & -0.073 \\
\hline Regional chain & -0.056 & -0.083 & -0.095 & -0.041 & -0.062 & -0.042 & -0.100 & -0.055 \\
\hline Local chain & -0.057 & -0.072 & -0.079 & -0.055 & -0.056 & -0.050 & -0.083 & 0.061 \\
\hline \multicolumn{9}{|c|}{ Panel B: Firm exit rates } \\
\hline Intercept & 0.097 & 0.158 & 0.136 & 0.115 & 0.162 & 0.119 & 0.173 & 0.139 \\
\hline \multicolumn{9}{|l|}{ Time period } \\
\hline $1976-1980$ & 0.032 & -0.014 & 0.020 & 0.083 & -0.005 & 0.037 & 0.045 & 0.029 \\
\hline 1981-1985 & 0.018 & 0.000 & 0.017 & 0.044 & -0.009 & 0.021 & 0.027 & 0.011 \\
\hline 1986-1990 & 0.012 & 0.000 & 0.017 & 0.017 & -0.012 & 0.006 & 0.013 & 0.003 \\
\hline 1991-1995 & 0.006 & -0.015 & -0.004 & -0.002 & 0.005 & -0.004 & -0.009 & -0.005 \\
\hline \multicolumn{9}{|l|}{ Market type } \\
\hline Metro & 0.019 & 0.014 & 0.027 & 0.010 & 0.017 & 0.021 & -0.007 & 0.004 \\
\hline Micro & 0.007 & 0.004 & 0.007 & 0.001 & 0.010 & 0.002 & -0.004 & 0.001 \\
\hline \multicolumn{9}{|l|}{ Firm type } \\
\hline National chain & -0.058 & -0.120 & -0.089 & -0.056 & -0.100 & -0.071 & -0.081 & -0.058 \\
\hline Regional chain & -0.036 & -0.053 & -0.061 & -0.035 & -0.055 & -0.038 & -0.069 & -0.036 \\
\hline Local chain & -0.061 & -0.069 & -0.074 & -0.057 & -0.067 & -0.061 & -0.081 & -0.065 \\
\hline
\end{tabular}

Source: Own calculations from the LBD.

Notes: Unit of Observation is a \{county, year, firm type\} cell. Regressions are run by 2-digit SIC with controls for time period, market type, and firm type. All coefficients are significant at the 5 percent level.

have grown larger over time, perhaps as a response to competitive pressures from chain stores.

Our analysis by county market type shows that rural markets are still served by a relatively large number of small mom-and-pop stores. These areas are experiencing net losses of this type of store. Our regional analysis shows that there are fewer competitors in larger markets, but competition in these markets is marked by higher firm turnover across all firm types.

The chapter also shows interesting differences across broad retail industries. Chain stores and mom-and-pop stores appear to be able to coexist in some industries better than others. Independent general merchandise stores and apparel and accessories store owners are disappearing from 
many markets while independent eating and drinking places can still be found in most markets.

In future work, we will delve deeper into the relationship between market size and market structure. How does the mix of ownership types change as market size changes? How does firm turnover change as market size changes? Asplund and Nocke (2006) develop a model with predictions regarding firm turnover and market size. They argue that turnover should be higher in larger markets. The LBD is ideal to look at this issue. How does firm size change in response to changes in market size? We can examine over a long period of time the relationship between establishment/firm size and how it varies across firm type.

\section{References}

Asplund, M., and V. Nocke. 2006. Firm turnover in imperfectly competitive markets. Review of Economic Studies 73 (2): 295-327.

Bagwell, K., G. Ramey, and D. F. Spulber. 1997. Dynamic retail price and investment competition. RAND Journal of Economics 28 (2): 207-27.

Basker, E. 2005. Job creation or destruction? Labor-market effects of Wal-Mart expansion. Review of Economics and Statistics 87 (1): 174-83.

Bayard, K., and S. D. Klimek. 2004. Creating a historical bridge for manufacturing between the Standard Industrial System and the North American Industry Classification System. 2003 Proceedings of the American Statistical Association, Business and Economic Statistics Section (CD-ROM): 478-84.

Campbell, J., and H. Hopenhayn. 2005. Market size matters. Journal of Industrial Economics 53 (1): 1-25.

Davis, S. J., J. C. Haltiwanger, and S. Schuh. 1996. Job creation and destruction. Cambridge, MA: MIT Press.

Dinlersoz, E. M. 2004. Firm organization and the structure of retail markets. Journal of Economics and Management Strategy 13 (2): 207-40.

Doms, M. E., R. S. Jarmin, and S. D. Klimek. 2004. Information technology investment and firm performance in U.S. retail trade. Economics of Innovation and New Technology 13 (7): 595-613.

Dunne, T., M. J. Roberts, and L. Samuelson. 1988. Patterns of Firm Entry and Exit in U.S. Manufacturing Industries. RAND Journal of Economics 19 (4): 495-515.

Ellickson, P. B. 2005. Supermarkets as a natural oligopoly. Duke University Department of Economics. Working paper 05-04.

Foster, L. S., J. Haltiwanger, and C. J. Krizan. 2006. Market selection, reallocation and restructuring in the U.S. retail trade sector in the 1990s. Review of Economics and Statistics 88 (4): 748-58.

Holmes, T. J. 2001. Bar codes lead to frequent deliveries and superstores. RAND Journal of Economics 34 (4): 708-25.

Jarmin, R. S., and J. Miranda. 2002. The longitudinal research database. Center for Economic Studies. CES Working paper CES-WP-02-17.

. Forthcoming. The impact of Hurricane Katrina on business establishments. Journal of Business Valuation and Economic Loss Analysis. 
McKinsey Global Institute. 2002. How IT Enables Productivity Growth MGI Reports, November. Available at www.mckinsey.com/knowledge/mgi/IT/

Miranda, J. 2001. LBD documentation: Geography. Center for Economic Studies, U.S. Census Bureau, Technical Notes CES-TN-2001-02, January.

Office of Management and Budget. 2000. Standards for defining metropolitan and micropolitan statistical areas. Federal Register 65 (249): 82228-38.

Sieling, M., B. Friedman, and M. Dumas. 2001. Labor productivity in the retail trade industry 1987-99. Monthly Labor Review Online 124 (12): 3-14.

U.S. Bureau of the Census. 1971. Census of business, 1967; Vol. I, Retail tradesubject reports. Washington, D.C.: U.S. Government Printing Office.

. 1994. Statistical abstract of the United States: 1994 (114th edition) Washington, D.C.: U.S. Government Printing Office.

\section{Comment Jeffrey R. Campbell}

Technology introduction takes place firm-by-firm and establishment-byestablishment. Even a good idea that falls from the sky (the classic neutral technology shock) must be read and incorporated into a production plan. For this reason, the analysis of individual producers' birth, growth, and death occupies a central place in productivity analysis. The Longitudinal Research Database provided the first observations of this process for the United States' Manufacturing sector, and its analysis by Dunne, Roberts, and Samuelson (1988), Bartelsman and Dhrymes (1998), and others created a new appreciation of creative destruction's contribution to productivity growth. Of course, these empirical developments would have been impossible without the contributions of Jovanovic (1982) and Hopenhayn (1992) to the theory of industry dynamics.

Manufacturing led U.S. economic growth through the 1960s, but Retail Trade and Services have worn the yellow jersey since then. Further progress relating productivity growth to industry dynamics therefore requires our empirical and theoretical work to catch up to this new leading sector. Jarmin, Klimek, and Miranda have given us a substantial push in this direction. Although they are not the first to examine producer-level data from Retail Trade, they are the first (to my knowledge) to do so in light of that sector's central economic fact: the replacement of stand-alone momand-pop stores by large chain stores with low prices. Today, Wal-Mart's rise occupies the headlines, but regional and nation chain growth inspired the anti-chain-store movement of the 1920s and 1930s. The specific players and their tactics have changed, but the issues at hand remain the same: do

Jeffrey R. Campbell is a senior economist at the Federal Reserve Bank of Chicago and a faculty research fellow of the National Bureau of Economic Research. E-mail: jcampbell @) frbchi.org 